\title{
NERVE GRAFTING IN BRACHIAL PLEXUS INJURIES
}

\author{
RESULTS OF FREE GRAFTS IN 90 PATIENTS
}

NAOYUKI OCHIAI, AKIRA NAGANO, HIROSHI SUGIOKA, TETSUYA HARA

From the University of Tokyo and Hiroo Municipal Hospital, Tokyo, Japan

W e have assessed the efficacy of free nerve grafts in 90 cases of brachial plexus injury. Relatively good recovery of the elbow flexor and extensor muscles and of those of the shoulder girdle was found but recovery of the flexors and extensors of the forearm and of the intrinsic muscles of the hand was extremely poor.

Poor results were found when spinal nerve roots seemed normal to the touch and appeared intact but had abnormal somatosensory evoked potentials or myelography. Recovery of the deltoid and infraspinatus muscles was better when injury had occurred to the circumflex and suprascapular nerves rather than to the plexus itself, perhaps because these nerves were explored in their entirety to determine the presence of multiple lesions.

It is important to visualise the entire nerve thoroughly to assess the overall condition. Thorough exploration of the plexus and the use of intraoperative recording of somatosensory evoked potentials are essential.

J Bone Joint Surg [Br] 1996;78-B:754-8.

Received 3 November 1995; Accepted after revision 6 February 1996

Despite the major progress which has been made over the last decade in both diagnostic procedures (Landi et al 1980; Sugioka et al 1982; Nagano et al 1989) and microsurgical techniques (Millesi 1977), the surgical management of brachial plexus injuries remains a challenge. Repair may be accomplished by nerve transfer and by reconstruction,

N. Ochiai, MD, Director

Department of Orthopaedic Surgery, Kanto Teishin Hospital, 5-9-22 Higashi Gotanda Shinagawa-ku, Tokyo, Japan.

A. Nagano, MD, Associate Professor

H. Sugioka, MD, Clinical Fellow

Department of Orthopaedic Surgery, Faculty of Medicine, University of Tokyo, 7-3-1 Hongo Bunkyo-ku, Tokyo, Japan.

T. Hara, MD, Director

Ebara Municipal Hospital, 4-5-10 Higashi Yukigaya Oota-ku, Tokyo, Japan.

Correspondence should be sent to Dr N. Ochiai.

(C)1996 British Editorial Society of Bone and Joint Surgery 0301-620X/96/41219\$2.00 usually using autologous free nerve grafts. The results, however, are still far from satisfactory.

Our aim was to focus on the results of nerve grafting in brachial plexus injuries in terms of muscle recovery itself and to describe what should be expected from nerve grafting and what could be improved upon.

\section{PATIENTS AND METHODS}

We have reviewed 90 patients with brachial plexus injury who were operated on using free nerve grafting and followed up for more than 18 months at the Departments of Orthopaedics of the University of Tokyo and Hiroo Municipal Hospital between 1981 and 1993. Patients with complete avulsion of all five roots were excluded. The average age at injury was 20.9 years (5 to 49) and there were 85 males and five females. The cause of injury was a roadtraffic accident in 85 cases, resection of a tumour in one, a conveyor-belt accident in one, a rope-lift accident in one, a dog-bite injury in one, and a sports injury in one.

We explored the brachial plexus to evaluate the level of the lesions using intraoperative recordings of somatosensory evoked potentials (SEPs) induced by direct nerve-root stimulation and recorded at the scalp (C3 or C4, 10 to 20 system and Fz, reference electrode) (Sugioka et al 1982). The active electrode was on the parietal somatosensory cortex and the reference electrode on the midfrontal cortex. Recordings were taken at least twice from each root for reproducibility. As a control, we measured the SEPs induced by stimulating the ipsilateral intact roots or the contralateral median nerve. We also assessed the myelographic findings (Nagano et al 1989) to decide whether the injured nerve roots were suitable for use as recipients for a nerve graft.

From a therapeutic viewpoint we classified patients into two groups, a brachial plexus injury (BPI) group and an axillary/suprascapular nerve injury group $(\mathrm{AX}+\mathrm{SS})$. In the latter, functional impairment was limited to, or was most severe in the deltoid, supraspinatus and infraspinatus muscles (Ochiai et al 1988). The BPI group included both supra- and infraclavicular lesions.

For recording SEPs the BPI patients were positioned on their back and the plexus approached through a zig-zag incision along the posterior border of the sternomastoid muscle, the clavicle and the deltopectoral groove to the upper arm. Recently, we have explored the supraclavicular 
Table I. Sites of proximal attachment of the graft

\begin{tabular}{lc}
\hline & Number \\
\hline C4 & 2 \\
C5 & 39 \\
C6 & 11 \\
C7 & 4 \\
Upper trunk & 18 \\
Middle trunk & 2 \\
Lower trunk & 3 \\
Lateral cord & 5 \\
Posterior cord & 2 \\
Medial cord & 1 \\
Suprascapular nerve & 18 \\
Axillary nerve & 28 \\
Musculocutaneous nerve & 5 \\
Median nerve & 1 \\
Radial nerve & 3 \\
\hline
\end{tabular}

Table II. Sites of distal attachment of the graft

\begin{tabular}{lc}
\hline & Number \\
\hline Upper trunk & 8 \\
Middle trunk & 3 \\
Lower trunk & 0 \\
Lateral cord & 8 \\
Posterior cord & 9 \\
Medial cord & 1 \\
Accessory nerve & 1 \\
Suprascapular nerve & 31 \\
Axillary nerve & 42 \\
Pectoral nerve & 2 \\
Musculocutaneous nerve & 22 \\
Median nerve & 17 \\
Radial nerve & 9 \\
Ulnar nerve & 1
\end{tabular}

part through a transverse incision parallel to the clavicle with a second incision along the deltopectoral groove for the infraclavicular portion.

The AX+SS patients were placed in the decubitus position and a sabre-cut incision used starting near the axillary fold and continuing along the deltopectoral groove over the clavicle to the quadrilateral space. The upper part of the trapezius muscle was detached from the bony insertion and the posterior part of the deltoid muscle mobilised from the scapular origin. This allowed us to explore all of the suprascapular and axillary nerves (Ochiai et al 1988).

We used mainly the sural nerves as autografts. The exceptions were one patient in whom a cutaneous nerve of the forearm and four in whom vascularised ulnar nerves were used. The cross-section of the stump of the root or trunk was covered as much as possible by the graft. Two sutures were usually used at each end of the graft, sometimes with fibrin glue. The average duration between injury and repair was 3.4 months (1 to 10) and the average followup was 35 months (18 to 96 ).

Evaluation of the repair is not easy since the extent of injury is different in every case, and the operation performed differed in each patient. We graded the result by manual testing of the muscles which were reinnervated by operation. Unless there was a total lesion of the brachial plexus it is difficult to assess which part of the recovery can be absolutely attributed to surgical repair. However carefully these assessments are carried out some inaccuracy will inevitably appear.

\section{RESULTS}

The patterns of grafting were so varied that it was impossible to summarise them systematically. The proximal and distal sites of attachment of the grafts are listed in Tables I and II, respectively. Table III gives the patterns for grafting used in 57 patients with paralysis of the deltoid muscle.

The rates of recovery for each muscle are shown in Table IV. Recovery to more than MRC grade 3 occurred in the deltoid in $59.7 \%$, the infraspinatus in $47.2 \%$, the pectoralis major in $42.9 \%$, the biceps in $74.3 \%$, the triceps in $38.9 \%$, the extensor digitorum communis in $11.8 \%$, the flexor digitorum superficialis in $13 \%$, and the flexor pollicis longus in $13 \%$. Useful recovery was found in the elbow flexor and extensor and shoulder girdle muscles. The results in the forearm flexors and extensors were usually poor. We had too few patients to comment on recovery in the ulnar intrinsic muscles but the abductor pollicis brevis fared poorly.

The recovery of the biceps bore no relation to the length of the graft (Fig. 1). Better recovery in the infraspinatus and

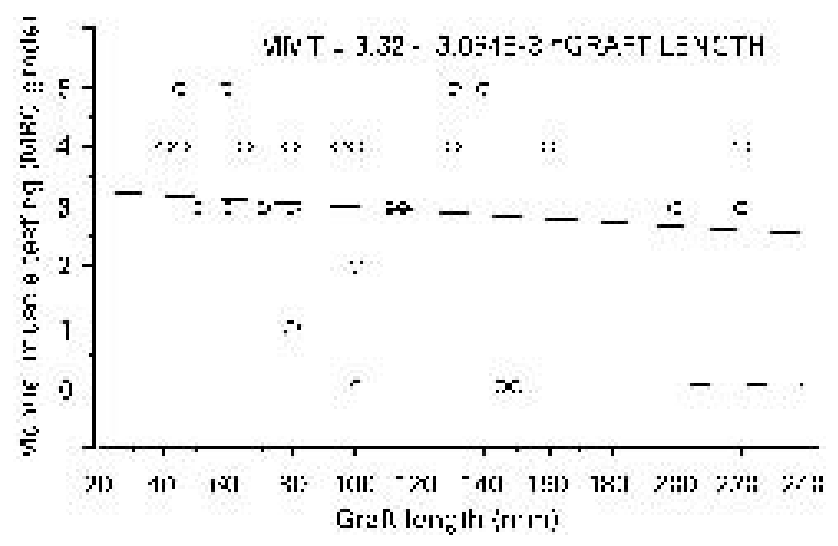

Fig. 1

Correlation between graft length and muscle strength in the biceps. 
Table III. The graft patterns to the deltoid in 57 patients

\begin{tabular}{llll}
\hline & Destination & & \\
\cline { 2 - 4 } Proximal end & Axillary nerve & Posterior cord & Upper trunk \\
\hline C4 & 9 & 3 & 1 \\
C5 & 1 & 2 & 1 \\
C6 & & & 1 \\
C5,6 & 4 & 2 & 3 \\
Upper trunk & & & 1 \\
Posterior division of upper trunk & 28 & 1 & \\
Axillary nerve & & & \\
Posterior cord & &
\end{tabular}

Table IV. The rate of recovery (percentage) in each muscle as measured by MRC grading

\begin{tabular}{|c|c|c|c|c|c|c|c|}
\hline \multirow[b]{2}{*}{ Muscle } & \multirow[b]{2}{*}{ Number } & \multicolumn{6}{|c|}{ Manual muscle testing (MRC grade) } \\
\hline & & 5 & 4 & 3 & 2 & 1 & $\mathbf{0}$ \\
\hline Infraspinatus & 36 & 5.6 & 19.4 & 22.2 & 22.2 & 19.4 & 11.1 \\
\hline Deltoid & 57 & 10.5 & 21.1 & 28.1 & 14.0 & 19.3 & 7.0 \\
\hline Pectoralis major & 14 & 0.0 & 28.6 & 14.3 & 35.7 & 7.1 & 14.3 \\
\hline Biceps & 35 & 14.3 & 25.7 & 34.3 & 5.7 & 8.6 & 11.4 \\
\hline Brachioradialis & 25 & 0.0 & 0.0 & 8.0 & 16.0 & 20.0 & 56.0 \\
\hline Triceps & 18 & 0.0 & 16.7 & 22.2 & 16.7 & 22.2 & 22.2 \\
\hline Extensor carpi radialis & 22 & 0.0 & 4.5 & 13.6 & 9.1 & 27.3 & 45.5 \\
\hline Extensor digitorum communis & 17 & 0.0 & 0.0 & 11.8 & 0.0 & 5.9 & 82.4 \\
\hline Extensor carpi ulnaris & 17 & 0.0 & 0.0 & 0.0 & 0.0 & 11.8 & 88.8 \\
\hline Extensor pollicis longus & 17 & 0.0 & 0.0 & 0.0 & 0.0 & 0.0 & 100.0 \\
\hline Flexor carpi radialis & 32 & 0.0 & 6.3 & 6.3 & 18.8 & 6.3 & 62.5 \\
\hline Palmaris longus & 17 & 0.0 & 5.9 & 0.0 & 17.6 & 5.9 & 70.6 \\
\hline Flexor carpi ulnaris & 2 & 0.0 & 50.0 & 50.0 & 0.0 & 0.0 & 0.0 \\
\hline Flexor digitorum sublimis & 23 & 0.0 & 0.0 & 13.0 & 13.0 & 4.3 & 69.6 \\
\hline Flexor pollicis longus & 23 & 0.0 & 4.3 & 8.7 & 13.0 & 4.3 & 69.6 \\
\hline Flexor digitorum profundus & 2 & 0.0 & 50.0 & 50.0 & 0.0 & 0.0 & 0.0 \\
\hline Abductor pollicis brevis & 17 & 0.0 & 0.0 & 0.0 & 0.0 & 0.0 & 100.0 \\
\hline Abductor digiti minimi & 2 & 0.0 & 0.0 & 0.0 & 0.0 & 0.0 & 100.0 \\
\hline
\end{tabular}

Table V. The level of recovery according to the MRC grading in the deltoid and infraspinatus in both groups

\begin{tabular}{llllllllll}
\hline & & \multicolumn{9}{c}{ Manual muscle testing (MRC Grade) } & \\
\cline { 5 - 8 } & Number & $\mathbf{5}$ & $\mathbf{4}$ & $\mathbf{3}$ & $\mathbf{2}$ & $\mathbf{1}$ & $\mathbf{0}$ & p value \\
\hline $\begin{array}{l}\text { Infraspinatus } \\
\text { BPI }\end{array}$ & 19 & 0 & 2 & 4 & 4 & 5 & 4 & \\
$\quad$ AX+SS & 17 & 2 & 5 & 4 & 4 & 2 & 0 & 0.0042 \\
$\begin{array}{l}\text { Deltoid } \\
\text { BPI }\end{array}$ & 34 & 1 & 6 & 8 & 4 & 11 & 4 & \\
AX+SS & 23 & 5 & 6 & 8 & 4 & 0 & 0 & 0.0002 \\
\hline
\end{tabular}


Table VI. Results in four patients in whom a spinal nerve root with normal SEPs and a normal myelogram was used

\begin{tabular}{lll}
\hline Case & Operative procedure & Result (MRC grade) \\
\hline 1 & C5-posterior division of upper trunk & $\begin{array}{l}\text { Deltoid } 0 \\
\text { Triceps } 1\end{array}$ \\
2 & Upper trunk-posterior cord & Deltoid 1 \\
& & Triceps 0 \\
3 & C5-axillary, suprascapular & Deltoid 1 \\
& & Infraspinatus 1 \\
4 & C5-axillary & Deltoid 1 \\
\hline
\end{tabular}

Table VII. Results in 11 patients in whom the spinal nerve roots appeared to be intact but the SEPs and/or the myelogram were abnormal

\begin{tabular}{llllll}
\hline & & & \multicolumn{3}{l}{ MRC grade } \\
\cline { 3 - 6 } SEPs & Myelogram & Number & $>\mathbf{3}$ & $\mathbf{1}$ & $\mathbf{0}$ \\
\hline Normal & Abnormal & 5 & 1 & 1 & 3 \\
Abnormal & Normal & 3 & & & 3 \\
Abnormal & Uncertain & 2 & & 2 & \\
Abnormal & Abnormal & 1 & & 1 & \\
\hline
\end{tabular}

deltoid was seen in the $\mathrm{AX}+\mathrm{SS}$ group than in the BPI group (Table V).

The quality of the proximal junction, especially of the spinal nerve root, is critical. In four patients the results were unsatisfactory in spite of using a spinal nerve root with normal SEPs and a normal myelogram (Table VI). These poor results were mainly found in procedures which attempted to reinnervate the deltoid. There were 11 cases in which the spinal nerve roots appeared to be intact but the SEPs and/or myelograms were abnormal. Grafting in these nerves also gave poor results (Table VII).

\section{DISCUSSION}

Many other authors have found good recovery of elbow flexor and extensor muscles and of the muscles around the shoulder girdle, but have encountered poor results in the forearm flexors and extensors and in the intrinsic muscles of the hand (Alnot 1988; Birch et al 1988; Hentz and Narakas 1988; Millesi 1988; Sedel 1988).

In our series recovery rates of more than MRC grade 3 on manual muscle testing in the biceps, infraspinatus, deltoid and triceps were $40 \%$ to $70 \%$. To obtain optimum results it is necessary to assess the state of both the proximal and distal sites which the graft must bridge. We explore the plexus if the myelogram indicates at least one root avulsion or in postganglionic lesions if there has been no sign of recovery after three months. Intraoperative recording of SEPs is mandatory to detect functional continuity to the spinal cord (Landi et al 1980; Sugioka et al 1982) and we advise that only spinal nerve roots which are shown to have normal conduction and a normal appearance on the myelogram are used. Theoretically, SEPs only indi- cate sensory function but in practice they may also reflect motor function.

Immunohistological studies have confirmed that degenerative or immature regenerative nerve fibres and scar tissue may be present in apparently normal spinal nerve roots (Okinaga et al 1990). Myelography and myeloCT scanning techniques have improved but false-positive and false-negative findings are inevitable (Roger, Travers and Laval-Jeantet 1988; Nagano et al 1989). The myelographic findings, however, should not be underestimated.

The condition of the distal destinations of the graft must also be confirmed. Brachial plexus injuries are usually due to traction and neural tissue may be torn along the course of the nerve. Double- or triple-level lesions are encountered relatively frequently (Alnot 1988; Ochiai et al 1988).

Generally, it has been found that the results of short nerve grafts are better than those of long grafts (Hentz and Narakas 1988; Chuang et al 1993). In our series the length of the graft to the biceps did not affect the result. In two cases the biceps still recovered to more than MRC grade 3 even with grafts as long as $25 \mathrm{~cm}$. The musculocutaneous nerve can be explored easily along its whole course, and this reinforces the view that the condition of both proximal and distal destinations is of great importance.

We assessed the result by MRC grading instead of using a functional evaluation of the upper limb, such as the Narakas score. The use of differing systems of assessment makes it difficult to compare the results of individual series. It is necessary to understand the limitations of repair of the brachial plexus in terms of the potential recovery of each muscle when planning reconstructive surgery. We have found that nerve grafts can be used to restore function in the shoulder and elbow, but will be of little value in the forearm and hand. We advise free muscle transplantation combined with nerve transfer for reconstruction of forearm muscle function if necessary (Akasaka, Hara and Takahashi 1991; Doi et al 1993).

No benefits in any form have been received or will be received from a commercial party related directly or indirectly to the subject of this article.

\section{REFERENCES}

Akasaka Y, Hara T, Takahashi M. Free muscle transplantation combined with intercostal nerve crossing for reconstruction of elbow flexion and wrist extension in brachial plexus injuries. Microsurgery 1991; 12:346-51.

Alnot JY. Traumatic brachial plexus palsy in the adult: retro- and infraclavicular lesions. Clin Orthop 1988;237:9-16.

Birch R, Dunkerton M, Bonney G, Jamieson AM. Experience with the free vascularised ulnar nerve graft in repair of supraclavicular lesions of the brachial plexus. Clin Orthop 1988;237:96-104.

Chuang DC, Epstein MD, Yeh MC, Wei FC. Functional restoration of elbow flexion in brachial plexus injuries: results in 167 patients (excluding obstetric brachial plexus injury). J Hand Surg [Am] 1993;18:285-91.

Doi K, Sakai K, Ihara K, et al. Reinnervated free muscle transplantation for extremity reconstruction. Plast Reconstr Surg 1993;91:872-83. 
Hentz VR, Narakas A. The results of microneurosurgical reconstruction in complete brachial plexus palsy: assessing outcome and predicting results. Orthop Clin North Am 1988;19:107-14.

Landi A, Copeland SA, Wynn Parry CB, Jones SJ. The role of somatosensory evoked potentials and nerve conduction studies in the surgical management of brachial plexus injuries. J Bone Joint Surg [Br] 1980;62-B:492-6.

Millesi H. Surgical management of brachial plexus injuries. J Hand Surg 1977;2:367-79.

Millesi H. Brachial plexus injuries: nerve grafting. Clin Orthop 1988;237:36-42.

Nagano A, Ochiai N, Sugioka H, Hara T, Tsuyama N. Usefulness of myelography in brachial plexus injuries. J Hand Surg $[\mathrm{Br}]$ 1989;14:59-64.
Ochiai N, Nagano A, Okinaga S, Murasima R, Tachibana S. Brachial plexus injuries: surgical treatment of combined injuries of the axillary and suprascapular nerves. J Jpn Soc Surg Hand 1988;5:151-5.

Okinaga S, Nagano A, Ochiai N, Yamamoto S, Tobimatsu H. Histopathological findings of SEPs absent roots in brachial plexus injuries. J Jpn Soc Surg Hand 1990;7:345-50.

Roger B, Travers V, Laval-Jeantet M. Imaging of posttraumatic brachial plexus injury. Clin Orthop 1988;237:57-61.

Sedel L. Repair of severe traction lesions of the brachial plexus. Clin Orthop 1988;237:62-6.

Sugioka H, Tsuyama N, Hara T, et al. Investigation of brachial plexus injuries by intraoperative cortical somatosensory evoked potentials. Arch Orthop Trauma Surg 1982;99:143-51. 